\title{
Sleep Disorders in Parkinson's Disease
}

\author{
${ }^{1}$ A Elavarsi, ${ }^{2}$ Garima Shukla
}

\begin{abstract}
Sleep disorders in Parkinson's disease (PD) have been recognized as one of the nonmotor symptoms of PD and is the common cause of poor quality of life in these patients, as motor symptoms are very well controlled by drugs as well as deep brain stimulation. Assessment and treatment of these disorders are essential for optimal management of the disease. This article presents a brief overview of various disorders and how to approach them.
\end{abstract}

Keywords: Excessive daytime sleepiness, Insomnia, Parkinson disease, Rapid eye movement sleep behavior disorder, Sleep.

How to cite this article: Elavarasi A, Shukla G. Sleep Disorders in Parkinson's Disease. Indian J Sleep Med 2017;12(3):44-48.

Source of support: Nil

Conflict of interest: None

\section{INTRODUCTION}

Sleep is a complex neurological state which provides rest and restores the energy levels. One-third of a person's life is spent in sleep, and various studies have shown that interruption of sleep affects the health of an individual. ${ }^{1}$ Poor sleep quality and quantity affect the quality of life and the health of the patient and also lead to adverse social and economic consequences. Sleep disorders which occur as a part of chronic diseases may have to be dealt with in addition to treatment of the primary disease in order to provide optimal care.

Sleep disorders are one of the most common groups of nonmotor symptoms of PD and are an important cause of impaired quality of life in these patients. ${ }^{2,3}$

\section{SLEEP DISORDERS IN PD}

The International Classification of Sleep Disorders (ICSD)-3 classification has mentioned seven broad categories of sleep disorders which are insomnia disorders, sleep-related breathing disorders, central disorders of hypersomnolence, circadian rhythm sleep-wake disorders, sleep-related movement disorders, parasomnias, and other sleep disorders. ${ }^{4}$ Of these, any of them may be associated with PD.

\footnotetext{
${ }^{1}$ Senior Resident, ${ }^{2}$ Professor and In-charge

${ }^{1,2}$ Department of Neurology, All India Institute of Medical Sciences, New Delhi, India

Corresponding Author: Garima Shukla, Professor and In-charge Department of Neurology, All India Institute of Medical Sciences New Delhi, India, Phone: +919811645328, e-mail: garimashukla@ hotmail.com
}

Some sleep disorders, such as rapid eye movement (REM) sleep behavior disorder (RBD) have been shown to be specifically related to PD and precede PD or other synucleinopathy by several years. Restless legs syndrome (RLS) has a dopaminergic pathway dysfunction, and is related to $\mathrm{PD}$. In patients with $\mathrm{PD}$, studies have reported varying prevalence of diseases, such as obstructive sleep apnea (OSA), excessive daytime sleepiness (EDS), and insomnia. These may have several causes and are found commonly in general population as well.

\section{EXCESSIVE DAYTIME SLEEPINESS VS DISTURBED NOCTURNAL SLEEP}

Sleep disorder in PD could be mainly categorized into EDS and disturbed nocturnal sleep. Excessive daytime sleepiness may itself be a consequence of poor nocturnal sleep, which may be due to multiple reasons. Motor disability, such as rigidity may lead to difficulty in turning ${ }^{5}$ or nonmotor features, such as autonomic dysfunction leading to nocturia, and urinary frequency ${ }^{6}$ could be causing fragmented sleep. Poor sleep quality could be iatrogenic, such as of drug-induced insomnia related to anticholinergic or dopaminergic drugs, due to "off" periods or due to dyskinesia related to dopaminergic drugs. ${ }^{7}$ Sleep-disordered breathing (SDB) as well as RBD may also contribute to poor sleep quality. Depression related to the disability may also be impairing sleep. ${ }^{8}$

\section{DIAGNOSTIC APPROACH}

The assessment of sleep-related problems in PD starts from history, given by the patient as well as the bed partner. Sleep disorders may be diagnosed based on various validated questionnaires available, such as Epworth's sleepiness scale (ESS), ${ }^{9}$ Pittsburg sleep quality index, ${ }^{10}$ or the PD sleep scale. ${ }^{11}$ On the contrary, objectively sleep parameters may be assessed by overnight polysomnography (PSG) and actigraphy.

A sleep log including various problems that the patient encounters during sleep as well as a review of the list of medications and a detailed neurologic and general medical history and examination are essential to arrive at a comprehensive diagnosis and optimal treatment.

\section{OCCURRENCE OF SLEEP DISTURBANCES IN PD}

Various studies have found that subjective sleep disturbances in PD patients range from 37 to $95 \%$. ${ }^{7,12-14}$ 
Ylikoski et al ${ }^{3}$ found that $26.2 \%$ of PD patients slept longer, $32.5 \%$ had a short sleep, $21.2 \%$ had poor sleep, and found sleep deprivation in $33.8 \%$, disrupted sleep in $47.4 \%$, and difficulties to fall asleep in $12.2 \%$ of patients in a questionnaire-based study. According to this study, depression, subjective negative stress, and fatigue were associated with longer sleep. Poor sleep and EDS were reported in those with shorter total sleep time and those with sleep deprivation.

Another study found that of the various nocturnal symptoms in PD, nocturia was the most prevalent $(91.5 \%)$ and hallucinations were the least (15\%). ${ }^{15}$

Chen at al ${ }^{16}$ conducted a meta-analysis of studies which looked at various nonmotor symptoms in PD patients; 332 studies met their inclusion criteria, and they found that the prevalence of RBD prevalence to be 5.3 times higher in PD patients (37\%) than in controls (7\%). The EDS was found in $33.9 \%$ of PD patients compared with $10.5 \%$ in the control population. In a meta-analysis of eight studies including 2,462 PD patients and 3,818 healthy controls, the overall prevalence of RBD symptoms in PD was 582/2462 (23.6\%) as compared with 131/3818 $(3.4 \%)$ in controls. ${ }^{17}$

\section{POLYSOMNOGRAPHY EVIDENCE OF SLEEP DISTURBANCES IN PD}

Though the prevalence of subjective sleep disturbances as evidenced by questionnaire-based studies is quite high in PD, PSG studies of patients have revealed conflicting data.

Fifteen consecutive, previously untreated PD patients without exposure to psychotropic, antidepressant drugs or benzodiazepines were evaluated with ESS and PSG, before and after starting on treatment with dopaminergic drugs. Dopaminergic drugs resulted in significant increase in mean percentage of stages 1 and 2 sleep. Mean ESS scores significantly increased and mean multiple sleep latency time (MSLT) decreased after dopaminergic treatment implying both subjective and objective poor sleep quality. Daytime sleepiness was not present in untreated patients, but occurred following dopaminergic treatment. ${ }^{18}$

On the contrary, Ferreira et al conducted a PSG-based study on 23 patients before starting on dopaminergic therapy, and on 12 of the 23 PD patients again after they were put on dopaminergic therapy, and found that sleep efficiency and other parameters improved significantly. ${ }^{19}$ An observational study that compared 33 PD patients with 37 age-matched normal controls found that apart from reduced mean REM sleep atonia (80 vs $93 \%$; $\mathrm{p}<0.05$ ), rest of the objective parameters, such as sleep time, sleep efficiency, indices, hour of arousals, awakenings, apnea / hypopnea, and periodic leg movements were similar in those with and without PD. ${ }^{20}$
In another PSG-based study, 70 PD patients and 70 age- and sex-matched controls were compared in which authors found that sleep efficiency decreased and sleep latency and arousal index were increased in the PD patients. Sleep efficiency and total sleep time were positively correlated with the Hoehn and Yahr stage. There was significant difference in the extent of hypopnea and hypoxemia, which were significantly different between the PD and control group. ${ }^{21}$

Thus, sleep parameters in PD depend on various factors, such as age, the stage of the disease, and the usage of dopaminergic drugs. ${ }^{22}$

\section{DRUG-RELATED SLEEP DISORDERS}

Dopaminergic drugs are the mainstay of treatment in PD and they improve the quality of life in terms of motor function. However, the dopaminergic agonists may cause a specific adverse effect, which was termed "sleep attack" by Frucht et $\mathrm{al}^{23}$ when they first described a series of eight cases in which patients who were on ropinirole and pramipexole met with motor vehicle accidents because they had fallen asleep without warning, and this resolved when the drugs were stopped. Patients may be on anticholinergic drugs or antidepressants/antipsychotics for depression or behavioral disturbances, which may cause insomnia and may precipitate or aggravate symptoms of RLS. Hypnogogic hallucinations may be frequently associated with dopamine agonist therapy, especially at higher doses, and in patients with fragmented nocturnal sleep, these may further enhance the disturbance, not only at initiation, but also throughout the night. ${ }^{18}$

\section{EXCESSIVE DAYTIME SOMNOLENCE IN PD}

Subjective EDS is the most important factor which affects the quality of life of PD patients as correlated by questionnaire-based studies. However, subjective EDS based on ESS of $>10$ was found in $46.3 \%$ of 134 consecutive patients of PD, and only $13.4 \%$ had MSLT-proven objective sleepiness during daytime. ${ }^{24}$ These symptoms of EDS were independent of various factors, such as motor disability, depression, medication, RLS, and others.

In a prospective cohort study of 153 drug-naive patients with early PD and 169 control participants assessed for EDS using ESS $>10$ and reevaluated after 1, 3 , and 5 years on medication, it was found that patients reported EDS more often than control participants at the time of diagnosis and during follow-up. The EDS in PD was found in $11.8 \%$ at baseline and $23.4 \%$ after 5 years. ${ }^{25}$

\section{OBSTRUCTIVE SLEEP APNEA IN PD}

The ICSD-3 lays down the diagnostic criteria for OSA. ${ }^{4}$ There are contradictory observations on the prevalence 
of OSA among patients with PD. While some studies have shown no higher than normal prevalence of OSA in PD, ${ }^{26,27}$ others have shown PD to have a possible protective effect on development of OSA. ${ }^{28,29}$ This is evidenced by a meta-analysis of five studies including a total of 322 cases and 6,361 controls in whom the odds ratio for the prevalence of OSA in PD as compared with controls was 0.60 [95\% confidence interval (CI) $0.44-0.81, \mathrm{p} 0.001]{ }^{30}$

In a narrative review, the authors studied seven PSG studies of SDB in PD patients. Of these, five studies reported similar or lower prevalence of SDB in patients when compared with healthy age-matched controls. Two studies reported less oxyhemoglobin desaturation during sleep among patients. The results were showing that PD patients were not at higher risk of SDB as compared with controls. ${ }^{31}$

Though PD protects against OSA, having OSA does not protect against the development of PD. Yeh et $\mathrm{al}^{32}$ followed up 16,730 patients diagnosed to have OSA and compared with an equal number of controls who were followed up for a mean duration of 5.6 years, and found a hazard ratio (HR) of 1.37 for OSA patients to develop $\mathrm{PD}$, especially among elderly males, and those with coexistent coronary artery disease, stroke, or chronic kidney disease. Sheu et $\mathrm{al}^{33}$ reported the data from Taiwan in which 1,532 patients with OSA and 7,500 controls were followed up for a period of 5 years, and found that PD developed in 1.24 and $0.63 \%$ in the OSA and control cohorts respectively, with HR of 2.26 (95\% CI 1.32-3.88) for developing PD. Among females, the adjusted HR of PD was 3.54 (95\% CI 1.50-8.34) for patients with OSA compared with those without.

The management of OSA in patients with PD is almost the same as in those with OSA only. ${ }^{34}$ A randomized study with crossover using CPAP vs placebo showed that therapeutic CPAP was effective in reducing apnea events, improving oxygen saturation, and deepening sleep in patients with PD and OSA. Moreover, CPAP treatment resulted in reduced daytime sleepiness measured by multiple sleep latency test. ${ }^{35}$

\section{SLEEP DISORDERS RELATED TO DOPAMINERGIC DYSFUNCTION AND NEURODEGENERATION}

\section{Restless Legs Syndrome in PD}

The prevalence of RLS has been found to be variable ranging from 0.8 to $24 \%$ and is higher among people with PD compared with the general population. ${ }^{36-48}$

It is difficult to distinguish RLS from dystonia, akathisia, neuropathy, and dyskinesias in patients with PD, especially in prevalence studies where health professionals other than qualified neurologists or sleep or movement disorder specialists are the assessors. ${ }^{49}$
In an 8-year follow-up study, it was found that the incidence of PD was $0.13 \%$ in those without RLS and $0.37 \%$ among patients fulfilling International RLS study group criteria ${ }^{50}$ for RLS. Prevalent RLS was associated with a HR of $2.57,95 \%$ CI 1.95 to 3.39 for development of PD as compared with RLS negative patients, which may suggest that PD is preceded by RLS. ${ }^{51}$

Since the PD patients are on a high dose of dopaminergic therapy, treatment mainly consists of nonpharmacologic measures including vibrating pads, near infrared spectroscopy, repetitive transcranial magnetic stimulation, or pneumatic compression. ${ }^{52}$ Alpha 2 ligands may be tried, though there are no randomized trials in this subgroup of patients. Rotigotine transdermal patch has been shown to be effective in phase III trials. ${ }^{53}$

\section{Sleep Behavior Disorder and PD}

Vivid dreams occur during normal REM sleep and is accompanied by skeletal muscle paralysis. ${ }^{54}$ Dream enactment is a result of skeletal muscle atonia, probably due to disruption of inhibitory brainstem function, leading to loss of skeletal muscle atonia. ${ }^{55}$ The RBD is diagnosed on PSG by REM associated with sleep without atonia. Follow-up studies have shown that up to $90 \%$ patients with RBD develop neurodegenerative disorder, most commonly PD, followed by other synnucleinopathy. ${ }^{55}$

In a video PSG study on 158 newly diagnosed drugnaïve PD patients and 110 age-, sex, and educationmatched healthy controls, $51 \%$ of PD patients and $15 \%$ of controls had RBD. ${ }^{56}$

In the Indian study by Vibha et $\mathrm{al}^{57}$ it was found that 26 of 134 (19.4\%) patients had RBD, and none of them were familial cases. The RBD in these patients was much less violent as compared with those described in Western literature, and was mostly vocalization or limb movement. There was an increased occurrence of hallucinations in patients with RBD. The prevalence of other sleep symptoms, such as insomnia, nocturnal awakenings, early morning awakenings, and snoring were higher in PD patients with RBD as compared with those without. ${ }^{58}$

\section{CONCLUSION}

Sleep disorders are, as discussed above, the major causes of morbidity among the nonmotor symptoms of PD, and some of the causes of EDS may be due to motor disability or disease related, which may improve on optimum treatment of PD. Among the premotor manifestations of PD also, sleep disturbances like RBD are common, as is the depression-associated insomnia. However, RLS may be associated with increased risk of developing PD in future, while RBD has a proven role as a harbinger of clinical PD (and other neurodegenerative conditions). More studies 
are required to guide treatment of these specific sleep disorders in PD, because as of today, the treatment is based on extrapolating data from studies in non-PD patients. Multiple problems may be responsible for poor sleep in a given patient and individualizing treatment decisions may help improve the quality of life in PD patients.

\section{ACKNOWLEDGMENT}

Dr Anupama Gupta's help with the bibliography is sincerely acknowledged.

\section{REFERENCES}

1. Kumar VM. Sleep and sleep disorders. Indian J Chest Dis Allied Sci 2008 Jan-Mar;50(1):129-135.

2. Scaravilli T, Gasparoli E, Rinaldi F, Polesello G, Bracco F. Health-related quality of life and sleep disorders in Parkinson's disease. Neurol Sci 2003 Oct;24(3):209-210.

3. Ylikoski A, Martikainen K, Sieminski M, Partinen M. Sleeping difficulties and health-related quality of life in Parkinson's disease. Acta Neurol Scand 2017 Apr;135(4):459-468.

4. American Academy of Sleep Medicine (AASM). ICSD-3 online version. Darien (IL): AASM; [cited 2017 May 2]. Available from: http:/ / www.aasmnet.org/store/product.aspx?pid=849.

5. Louter M, vanSloun RJ,PevernagieDA,ArendsJB,CluitmansPJ, Bloem BR, Overeem S. Subjectively impaired bed mobility in Parkinson disease affects sleep efficiency. Sleep Med 2013 Jul;14(7):668-674.

6. Vaughan CP, Juncos J, Trotti LM, Johnson TM, Bliwise DL. Nocturia and overnight polysomnography in Parkinson disease. Neurourol Urodyn 2013 Nov;32(8):1080-1085.

7. Louter M, Aarden WC, Lion J, Bloem BR, Overeem S. Recognition and diagnosis of sleep disorders in Parkinson's disease. J Neurol 2012 Oct;259(10):2031-2040.

8. Knie B, Mitra MT, Logishetty K, Chaudhuri KR. Excessive daytime sleepiness in patients with Parkinson's disease. CNS Drugs 2011 Mar;25(3):203-212.

9. Johns MW. A new method for measuring daytime sleepiness: the Epworth sleepiness scale. Sleep 1991 Dec;14(6):540-545.

10. Buysse DJ, Reynolds CF, Monk TH, Berman SR, Kupfer DJ. The Pittsburgh Sleep Quality Index: a new instrument for psychiatric practice and research. Psychiatry Res 1989 May;28(2):193-213.

11. Chaudhuri K, PalS, DiMarco A, Whately-Smith C, Bridgman K, Mathew R, Pezzela F, Forbes A, Hogl B, Trenkwalder C. The Parkinson's disease sleep scale: a new instrument for assessing sleep and nocturnal disability in Parkinson's disease. J Neurol Neurosurg Psychiatry 2002 Dec;73(6):629-635.

12. Lees AJ, Blackburn NA, Campbell VL. The nighttime problems of Parkinson's disease. Clin Neuropharmacol 1988 Dec;11(6):512-519.

13. Tandberg E, Larsen JP, Karlsen K. A community-based study of sleep disorders in patients with Parkinson's disease. Mov Disord 1998 Nov;13(6):895-899.

14. Martinez-Martin P, Schapira AH, Stocchi F, Sethi K, Odin P, MacPhee G, Brown RG, Naidu Y, Clayton L, Abe K, et al. Prevalence of nonmotor symptoms in Parkinson's disease in an international setting; study using nonmotor symptoms questionnaire in 545 patients. Mov Disord 2007 Aug;22(11):1623-1629.
15. Horváth K, Aschermann Z, Acs P, Bosnyák E, Deli G, Pál E, Janszky J, Faludi B, Késmárki I, Komoly S, et al. Is the MDSUPDRS a good screening tool for detecting sleep problems and daytime sleepiness in Parkinson's disease? Parkinsons Dis 2014 Nov;2014:806169.

16. Chen H, Zhao EJ, Zhang W, Lu Y, Liu R, Huang X, CiesielskiJones AJ, Justice MA, Cousins DS, Peddada S. Meta-analyses on prevalence of selected Parkinson's nonmotor symptoms before and after diagnosis. Transl Neurodegener 2015 Jan;4(1):1.

17. Zhang J, Xu CY, Liu J. Meta-analysis on the prevalence of REM sleep behavior disorder symptoms in Parkinson's disease. BMC Neurol 2017 Feb;17(1):23.

18. Kaynak D, Kiziltan G, Kaynak H, Benbir G, Uysal O. Sleep and sleepiness in patients with Parkinson's disease before and after dopaminergic treatment. Eur J Neurol 2005 Mar;12(3):199-207.

19. Ferreira T, Prabhakar S, Kharbanda PS. Sleep disturbances in drug naïve Parkinson's disease (PD) patients and effect of levodopa on sleep. Ann Indian Acad Neurol 2014 Oct;17(4):416-419.

20. Diederich NJ, Rufra O, Pieri V, Hipp G, Vaillant M. Lack of polysomnographic Non-REM sleep changes in early Parkinson's disease. Mov Disord 2013 Sep;28(10):1443-1446.

21. Mao ZJ, Liu CC, JI SQ, Yang QM, Ye HX, Han HY, Xue Z. Clinical characteristics of sleep disorders in patients with Parkinson's disease. J Huazhong Univ Sci Technol Med Sci 2017 Feb;37(1):100-104.

22. Rye DB, Bliwise DL, Dihenia B, Gurecki P. Daytime sleepiness in Parkinson's disease. J Sleep Res 2000 Mar;9(1):63-69.

23. Frucht S, Rogers JD, Greene PE, Gordon MF, Fahn S. Falling asleep at the wheel: motor vehicle mishaps in persons taking pramipexole and ropinirole. Neurology 1999 Jun;52(9): 1908-1910.

24. Cochen De Cock V, Bayard S, Jaussent I, Charif M, Grini M, Langenier MC, Yu H, Lopez R, Geny C, Carlander B, et al. Daytime sleepiness in Parkinson's disease: a reappraisal. PLoS One 2014 Sep;9(9):e107278.

25. Tholfsen LK, Larsen JP, Schulz J, Tysnes OB, Gjerstad MD. Development of excessive daytime sleepiness in early Parkinson disease. Neurology 2015 Jul;85(2):162-168.

26. Diederich NJ, Vaillant M, Leischen M, Mancuso G, Golinval S, Nati R, Schlesser M. Sleep apnea syndrome in Parkinson's disease. A case-control study in 49 patients. Mov Disord 2005 Nov;20(11):1413-1418.

27. Cochen De Cock V, Abouda M, Leu S, Oudiette D, Roze E, Vidailhet M, Similowski T, Arnulf I. Is obstructive sleep apnea a problem in Parkinson's disease? Sleep Med 2010 Mar;11(3):247-252.

28. Yong MH, Fook-Chong S, Pavanni R, Lim LL, Tan EK. Case control polysomnographic studies of sleep disorders in Parkinson's disease. PLoS One 2011 Jul;6(7):e22511.

29. Trotti LM, Bliwise DL. No increased risk of obstructive sleep apnea in Parkinson's disease. Mov Disord 2010 Oct;25(13):2246-2249.

30. Zeng J, Wei M, Li T, Chen W, Feng Y, Shi R, Song Y, Zheng W, Ma W. Risk of obstructive sleep apnea in Parkinson's disease: a meta-analysis. PLoS One 2013 Dec;8(12):e82091.

31. da Silva-Júnior FP, do Prado GF, Barbosa ER, Tufik S, Togeiro SM. Sleep disordered breathing in Parkinson's disease: a critical appraisal. Sleep Med Rev 2014 Apr;18(2):173-178. 
32. Yeh NC, Tien KJ, Yang CM, Wang JJ, Weng SF. Increased risk of Parkinson's disease in patients with obstructive sleep apnea: a population-based propensity score-matched longitudinal follow-up study. Medicine (Baltimore) 2016 Jan;95(2):e2293.

33. Sheu JJ, Lee HC, Lin HC, Kao LT, Chung SD. A 5-year followup study on the relationship between obstructive sleep apnea and Parkinson disease. J Clin Sleep Med 2015 Dec;11(12):14031408 (2015).

34. Videnovic A. Management of sleep disorders in Parkinson's disease and multiple system atrophy. Mov Disord 2017 May;32(5):659-668.

35. Neikrug AB, Liu L, Avanzino JA, Maglione JE, Natarajan L, Bradley L, Maugeri A, Corey-Bloom J, Palmer BW, Loredo JS, et al. Continuous positive airway pressure improves sleep and daytime sleepiness in patients with Parkinson disease and sleep apnea. Sleep 2014 Jan;37(1):177-185.

36. Tan EK, Lum SY, Wong MC. Restless legs syndrome in Parkinson's disease. J Neurol Sci 2002 Apr;196(1-2):33-36.

37. Ondo WG, Vuong KD, Jankovic J. Exploring the relationship between Parkinson disease and restless legs syndrome. Arch Neurol 2002 Mar;59(3):421-424.

38. Krishnan PR, Bhatia M, Behari M. Restless legs syndrome in Parkinson's disease: a case-controlled study. Mov Disord 2003 Feb;18(2):181-185

39. Nomura T, Inoue Y, Miyake M, Yasui K, Nakashima K. Prevalence and clinical characteristics of restless legs syndrome in Japanese patients with Parkinson's disease. Mov Disord 2006 Mar;21(3):380-384

40. Gómez-Esteban JC, Zarranz JJ, Tijero B, Velasco F, Barcena J, Rouco I, Lezcano E, Lachen MC, Jauregui A, Ugarte A. Restless legs syndrome in Parkinson's disease. Mov Disord 2007 Oct;22(13):1912-1916.

41. Loo HV, Tan EK. Case-control study of restless legs syndrome and quality of sleep in Parkinson's disease. J Neurol Sci 2008 Mar;266(1-2):145-149.

42. Peralta CM, Frauscher B, Seppi K, Wolf E, Wenning GK, Högl B, Poewe W. Restless legs syndrome in Parkinson's disease. Mov Disord 2009 Oct;24(14):2076-2080.

43. Verbaan D, van Rooden SM, van Hilten JJ, Rijsman RM. Prevalence and clinical profile of restless legs syndrome in Parkinson's disease. Mov Disord 2010 Oct;25(13):2142-2147.

44. Angelini M, Negrotti A, Marchesi E, Bonavina G, Calzetti S. A study of the prevalence of restless legs syndrome in previously untreated Parkinson's disease patients: absence of co-morbid association. J Neurol Sci 2011 Nov;310(1-2):286-288.

45. Gjerstad MD, Tysnes OB, Larsen JP. Increased risk of leg motor restlessness but not RLS in early Parkinson disease. Neurology 2011 Nov;77(22):1941-1946.

46. Bhalsing K, Suresh K, Muthane UB, Pal PK. Prevalence and profile of Restless Legs Syndrome in Parkinson's disease and other neurodegenerative disorders: a case-control study. Parkinsonism Relat Disord 2013 Apr;19(4):426-430.
47. Fereshtehnejad SM, Shafieesabet M, Shahidi GA, Delbari A, Lökk J. Restless legs syndrome in patients with Parkinson's disease: a comparative study on prevalence, clinical characteristics, quality of life and nutritional status. Acta Neurol Scand 2015 Apr;131(4):211-218

48. Moccia M, Erro R, Picillo M, Santangelo G, Spina E, Allocca R, Longo K, Amboni M, Palladino R, Assante R, et al. A four-year longitudinal study on restless legs syndrome in Parkinson disease. Sleep 2016 Feb;39(2):405-412.

49. Högl B, Stefani A. Restless legs syndrome and periodic leg movements in patients with movement disorders: specific considerations. Mov Disord 2017 May;32(5):669-681.

50. Allen RP, Picchietti D, Hening WA, Trenkwalder C, Walters AS, Montplaisi J; Restless Legs Syndrome Diagnosis and Epidemiology workshop at the National Institutes of Health International Restless Legs Syndrome Study Group. Restless legs syndrome: diagnostic criteria, special considerations, and epidemiology: a report from the restless legs syndrome diagnosis and epidemiology workshop at the National Institutes of Health. Sleep Med 2003 Mar;4(2):101-119.

51. Szatmari S Jr, Bereczki D, Fornadi K, Kalantar-Zadeh K, Kovesdy CP, Molnar MZ. Association of restless legs syndrome with incident Parkinson disease. Sleep 2017 Feb;40(2): zsw065.

52. Winkelman JW, Armstrong MJ, Allen RP, Chaudhuri KR, Ondo W, Trenkwalder C, Zee PC, Gronseth GS, Gloss D, Zesiewicz T. Practice guideline summary: treatment of restless legs syndrome in adults: report of the Guideline Development Dissemination, and Implementation Subcommittee of the American Academy of Neurology. Neurology 2016 Dec;87(24):2585-2593.

53. Splinter MY. Rotigotine: transdermal dopamine agonist treatment of Parkinson's disease and restless legs syndrome. Ann Pharmacother 2007 Feb;41(2):285-295.

54. Iranzo A, Molinuevo JL, Santamaría J, Serradell M, Martí MJ, Valldeoriola F, Tolosa E. Rapid-eye-movement sleep behaviour disorder as an early marker for a neurodegenerative disorder: a descriptive study. Lancet Neurol 2006 Jul;5(7):572-577.

55. Howell MJ, Schenck CH. Rapid eye movement sleep behavior disorder and neurodegenerative disease. JAMA Neurol 2015 Jun;72(6):707-712.

56. Sixel-Döring F, Trautmann E, Mollenhauer B, Trenkwalder C. Rapid eye movement sleep behavioral events: a new marker for neurodegeneration in early Parkinson disease? Sleep 2014 Mar;37(3):431-438.

57. Vibha D, Shukla G, Goyal V, Singh S, Srivastava AK, Behari M. RBD in Parkinson's disease: a clinical case control study from North India. Clin Neurol Neurosurg 2011 Jul;113(6):472-476.

58. Vibha D, Shukla G, Singh S, Goyal V, Srivastava AK, Behari M. Lower prevalence of sleep disturbances in familial versus sporadic Parkinson's disease: a questionnaire based study. J Neurol Sci 2010 Aug;295(1-2):27-30. 